\title{
Aspek Hukum Pelestarian Lahan Basah pada Situs Ramsar di Indonesia (Studi terhadap Implementasi Konvensi Ramsar 1971 di Taman Nasional Tanjung Puting)
}

\author{
Alam Surya Anggara* \\ Fakultas Hukum Universitas Antakusuma \\ Jl. Iskandar No. 63 Kelurahan Madurejo, Pangkalan Bun, Kalimantan Tengah 74112
}

\begin{abstract}
The Ramsar Convention have been incorporated and implemented into Indonesian law. In practice, however, weak government's commitment implies non-synchronized regulations have remained so implementing the sustainable and wise use of wetlands has not been able to be pursued. The internal and external factors make the implementation of Ramsar Convention in Tanjung Puting not optimal. The purpose of this article is to analyze the implementation of the 1971 Ramsar Convention to the peatland ecosystem protection and management at Tanjung Puting National Park, Central Kalimantan, since it has been recognized as a Ramsar Site in Indonesia.
\end{abstract}

Keywords: ramsar convention, wetlands, peatland degradation, tanjung puting national park.

\section{Intisari}

Ketentuan-ketentuan dalam Konvensi Ramsar telah dilaksanakan dan ditransformasikan ke dalam peraturan perundang-undangan di Indonesia. Dalam praktik, masih lemahnya komitmen pemerintah sehingga berimplikasi pada masih ditemukannya peraturan-peraturan yang tidak sinkron, sehingga belum dapat melaksanakan komitmen pemanfaatan lahan basah secara bijaksana dan berkelanjutan. Pelaksanaan Konvensi Ramsar dalam perlindungan dan pengelolaan ekosistem gambut di Tanjung Puting yang belum optimal juga disebabkan oleh faktor internal dan eksternal. Penelitian ini bertujuan untuk menganalisis implementasi Konvensi Ramsar 1971 terkait perlindungan dan pengelolaan ekosistem gambut di Taman Nasional Tanjung Puting, Kalimantan Tengah, sejak ditetapkan sebagai Situs Ramsar di Indonesia.

Kata Kunci: konvensi ramsar, lahan basah, degradasi gambut, taman nasional tanjung puting.

\section{Pokok Muatan}



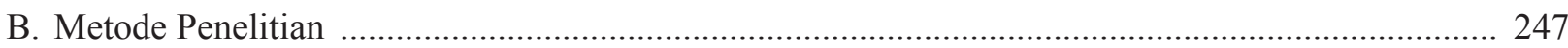

C. Hasil Penelitian dan Pembahasan ............................................................................................... 248

1. Gambaran Umum Mengenai Konvensi Ramsar 1971 ............................................................... 248

2. Implementasi Konvensi Ramsar 1971 di Indonesia .................................................................. 252

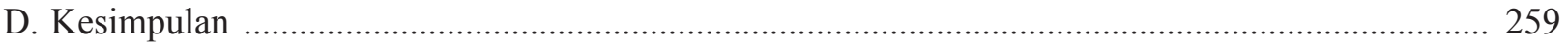




\section{A. Latar Belakang}

Pada tahun 1971, masyarakat internasional berhasil menyepakati Konvensi yang mengangkat kepedulian terhadap lahan basah. Konvensi Lahan Basah ini bernama Conventions on Wetlands of International Importance, Especially as Waterfowl Habitat atau biasa disebut sebagai Konvensi Ramsar. ${ }^{1}$ Pada awalnya Konvensi Ramsar fokus pada masalah burung air dan burung migran, namun dalam perkembangannya disepakati bahwa konservasi lahan basah dinilai lebih penting, serta berkembang pula kesadaran pada keutuhan keanekaragaman hayati dan aspek pemanfaatan lahan basah secara bijaksana (wise use). ${ }^{2}$ Tujuan utama konvensi ini untuk menghentikan perambahan dan perusakan lahan basah, yang merupakan ekosistem yang rapuh dan sensitif, serta keberadaannya sangat tergantung pada cara pemanfaatan dan usaha pelestariannya. ${ }^{3}$

Pada tahun 2018, ${ }^{4}$ sudah ada 2.303 situs Ramsar dengan luas mencapai 228 juta hektar yang telah didaftarkan oleh 169 Negara anggota dari enam Ramsar Region, yakni Afrika, Asia, Eropa, Amerika Latin dan Karibia, Amerika Utara, dan Oceania. ${ }^{5}$ Indonesia yang wilayahnya didominasi oleh lahan basah, ikut menjadi anggota Konvensi Ramsar dengan mengajukan Taman Nasional Berbak di Provinsi Jambi sebagai Situs Ramsar, dan mulai terikat sejak tahun $1992 .{ }^{6}$

Saat ini Indonesia memiliki 7 situs Ramsar, dengan luas mencapai 1.424.976 hektar. Ketujuh situs ini diantaranya, Taman Nasional (TN) Berbak seluas 162.700 hektar; TN Danau Sentarum (Kalimantan Barat) seluas 132.000 hektar; TN Wasur (Papua) seluas 413.810 hektar; TN Sembilang
(Sumatera Selatan) seluas 202.896 hektar; TN Rawa Aopa-Watumohai (Sulawesi Tenggara) seluas 105.194 hektar; Suaka Margasatwa Pulau Rambut (DKI Jakarta) seluas 90 hektar; dan TN Tanjung Puting (Kalimantan Tengah) seluas 408.286 hektar. $^{7}$

TN Tanjung Puting yang ditetapkan menjadi Situs Ramsar pada tahun 2013, menjadi representasi kawasan lahan basah paling penting di Kalimantan Tengah yang berfungsi sebagai reservoir air, serta berfungsi dalam menjaga proses hidrologi, biologi, dan ekologi dari ekosistem gambut. Kekayaan sumber daya lahan basah Tanjung Puting didominasi oleh hutan rawa gambut dan bakau.

Ancaman dan gangguan ekologis yang berdampak pada kerusakan ekosistem lahan basah masih terjadi meski Tanjung Puting telah ditetapkan sebagai Situs Ramsar. Hal ini disebabkan oleh kebakaran hutan dan lahan, illegal logging, dan konversi lahan menjadi perkebunan kelapa sawit. ${ }^{8}$ Tanjung Puting mengalami degradasi gambut yang mengakibatkan berubahnya habitat dan proses ekologi, serta mempengaruhi kelangsungan ekosistem gambut akibat pemanfaatannya yang tidak berkelanjutan. Kemudian masih ditemukan permasalahan seperti kesadaran masyarakat yang rendah untuk melindungi kawasan, pendanaan yang terbatas, serta lemahnya koordinasi dan pengawasan antar institusi.

Tulisan ini mengkaji implementasi Konvensi Ramsar 1971 terkait perlindungan dan pengelolaan ekosistem gambut di Taman Nasional Tanjung Puting sejak ditetapkan sebagai Situs Ramsar di Indonesia.

\footnotetext{
Konvensi ini diselenggarakan di Ramsar, Iran, dan mulai berlaku tanggal 21 Desember 1975.

Ramsar Convention Secretariat, 2016, An Introduction to The Convention on Wetlands, Ramsar Convention Secretariat, Gland, Switzerland, hlm.8.

Vera Batanjski, et.al., 2016, "Critical Legal and Environmental View on The Ramsar Convention in Protection from Invasive Plant Species: An Example of The Southern Pannonia Region”, International Environmental Agreements: Politics, Law and Economics, Springer Nature, Vol.16, Issue 6, hlm. 834.

Lihat https://www.ramsar.org.

C. Max Finlayson, et.al., 2011, "The Ramsar Convention and Ecosystem Based Approaches to the Wise Use and Sustainable Development of Wetlands", Journal of International Wildlife Law and Policy, Vol.14, No.3-4, hlm.182.

6 Keputusan Presiden Nomor 48 Tahun 1991 tentang Pengesahan Conventions on Wetlands of International Importance, Especially as Waterfowl Habitat.

Direktorat Kawasan Konservasi dan Bina Hutan Lindung, 2015, Pedoman ImplementasiKonvensi Ramsar di Indonesia, Direktorat Jenderal Perlindungan Hutan dan Konservasi Alam Kementerian Lingkungan Hidup dan Kehutanan, Jakarta, hlm.6.

Dian Novita, 2016, Penilaian Risiko Bencana Ekologis Taman Nasional Tanjung Puting Kalimantan Tengah, Tesis, Program Pascasarjana Program Studi Magister Manajemen Bencana Universitas Gadjah Mada, hlm.116.
} 


\section{B. Metode Penelitian}

Penelitian ini merupakan penelitian hukum normatif empiris. Bahan penelitian yang digunakan adalah data sekunder yang diperoleh dari penelitian kepustakaan dan data primer yang diperoleh dari penelitian lapangan. Lokasi penelitian dilakukan di ProvinsiKalimantan Tengah. Subyek penelitian yang menjadi responden meliputi Balai Taman Nasional Tanjung Puting, dan Kementerian Lingkungan Hidup dan Kehutanan Republik Indonesia. Data yang diperoleh dari penelitian kepustakaan dan penelitian lapangan (wawancara dengan responden dan narasumber) dikelompokan sesuai dengan permasalahan yang dibahas, kemudian diolah dan dianalisis secara kualitatif, sehingga diharapkan dapat memperoleh gambaran dan kesimpulan yang jelas untuk menjawab permasalahan hukum yang menjadi objek penelitian.

\section{Hasil Penelitian dan Pembahasan \\ 1. Gambaran Umum Mengenai Konvensi Ramsar 1971}

Konvensi Ramsar menjadi perjanjian internasional di bidang lingkungan hidup pertama yang menetapkan peraturan mengenai konservasi jenis ekosistem tertentu, yakni ekosistem lahan basah. ${ }^{9}$ Konvensi Ramsar atau Wetlands Convention dengan nama lengkapnya adalah Conventions on Wetlands of International Importance Especially as Waterfowl Habitat yang terdiri dari 12 pasal ini ditandatangani di kota Ramsar, Iran pada tanggal 2 Februari 1971 oleh 35 negara, 21 dari Eropa, dan 13 dari negara berkembang. Konvensi ini kemudian baru berlaku pada tanggal 21 Desember 1975 setelah memenuhi syarat ratifikasi berlakunya konvensi. ${ }^{10}$

Konvensi Internasional mengenai Lahan Basah ini disponsori oleh IUCN (International
Union for Conservation of Nature and Natural Resources), atau sekarang menjadi The World Conservation Union. IUCN merupakan NGO Internasional yang secara progresif berperan besar dalam mempengaruhi perkembangan perjanjian internasional terutama dalam bidang lingkungan hidup dan memiliki kontribusi besar dalam praktik implementasi di negara-negara yang telah terikat dengan kewajiban-kewajiban dari perjanjian internasional di bidang lingkungan hidup. ${ }^{11}$ IUCN yang memiliki The IUCN Environmental Law Centre dan IUCN Commission on Environmental Law telah membuat banyak sekali inisiatif serta kebijakan dan menyusun draf atau teks perjanjian internasional untuk negosiasi formal, seperti Konvensi Ramsar 1971. ${ }^{12}$

Tujuan utama Konvensi Ramsar adalah untuk menghentikan perambahan dan perusakan lahan basah yang terjadi saat ini dan di masa yang akan datang. Lahan basah merupakan ekosistem yang rapuh dan sensitif, oleh karena itu keberadaannya sangat tergantung pada cara pemanfaatan dan usaha pelestariannya. ${ }^{13}$ Pada hakikatnya, Konvensi Ramsar ingin menjamin pelestarian ekosistem lahan basah, mengingat kepentingannya dalam proses ekologi dan kekayaan yang terkandung di dalamnya seperti spesies flora dan fauna. ${ }^{14}$ Para pihak peserta mempunyai kewajiban-kewajiban yang harus dilaksanakan setelah menandatangani konvensi ini. Kewajiban setiap pihak adalah menjaga pelestarian lahan basah di wilayah negaranya dan kewajiban secara khusus adalah turut serta melindungi lahan basah yang memiliki kepentingan internasional yang termasuk dalam daftar yang telah ditentukan konvensi.

Dalam perkembangannya, naskah asli Konvensi Ramsar telah diamandemen dua

\footnotetext{
Philippe Sands, 2003, Principles of International Environmental Law, Cambridge University Press, hlm.33.

Andreas Pramudianto, "Kawasan Lahan Basah dalam Konsep Hukum Global dan Keberadaannya di Indonesia", Jurnal Lingkungan dan Pembangunan, Vol.14, No.1, 1994, hlm.2.

Patricia Birnie, et al., 2009, International Law \& The Environment, Third Edition, Oxford University Press, New York, hlm.47. Philippe Sands, Op.cit., hlm.114.

Vera Batanjski, et al., Op.cit., hlm.834.

Direktorat Konservasi Keanekaragaman Hayati, 2008, Konvensi dan Kerjasama Internasional Bidang Konservasi Keanekaragaman Hayati, Kementerian Kehutanan, hlm.8.
} 
kali, yakni pada Protokol Paris tahun 1982 dan Amandemen Regina tahun 1987. Protokol Paris diadopsi pada pertemuan luar biasa (Extraordinary Conference of the Contracting Parties (COP)) yang diselenggarakan di kantor pusat UNESCO Paris pada tanggal 3 Desember 1982. ${ }^{15}$ Protokol Paris berlaku resmi sejak 1986 dan mengatur tata cara melakukan amandemen terhadap konvensi (Pasal 10 bis) dan pengesahan naskah konvensi ke dalam beberapa bahasa (Arab, Perancis, Inggris, Jerman, Rusia, dan Spanyol). Sedangkan Amandemen Regina (The Second Amandment) diadopsi pada saat pertemuan luar biasa yang diselenggarakan di Regina, Kanada, tahun 1987. Secara umum amandemen tidak merubah substansi dasar dari konvensi, melainkan lebih berkaitan dengan masalah operasionalnya, antara lain menyangkut kewenangan COP, penetapan Standing Committee, anggaran dan penetapan Biro, dan Sekretariat Ramsar. Amandemen Regina berlaku sejak tanggal 1 Mei 1994.

Pada awalnya Konvensi Ramsar lebih berfokus pada masalah burung air dan burung migran. Dalam pembukaan konvensi dikemukakan alasan perlindungan internasional bagi lahan basah, yaitu karena fungsi ekologisnya sebagai pengatur pengairan dan sebagai wilayah dengan flora dan faunanya sendiri, yaitu burung unggas. ${ }^{16}$ Habitat utama bagi berbagai jenis burung air dan burung migran adalah lahan basah, seperti pantai, mangrove, muara sungai, dan rawa. Keberadaan lahan basah sebagai habitat yang mendukung kehidupan burung air dan burung migran digunakan sebagai tempat mencari makan dan beristirahat selama periode migrasinya. ${ }^{17}$ Akan tetapi, kerusakan lingkungan yang menyebabkan berkurangnya lahan basah menimbulkan kerugian yang berujung pada punahnya burung air dan burung migran.

Perkembangan pembahasan lebih lanjut menyepakati bahwa konservasi habitat lahan basah dinilai lebih penting daripada konservasi jenis atau spesies saja. Selanjutnya berkembang pada kesadaran keutuhan lingkungan termasuk keanekaragaman hayati, lalu saat ini lebih berfokus menyangkut seluruh aspek konservasi dan pemanfaatan lahan basah secara bijak (wise use). ${ }^{18}$ Konvensi Ramsar merupakan konvensi internasional yang secara spesifik mengatur tentang konservasi dan pemanfaatan lahan basah secara bijak. ${ }^{19}$

Pasal 1 ayat (1) Konvensi Ramsar menentukan definisi lahan basah yang meliputi daerah-daerah rawa, payau, lahan gambut, dan perairan alami atau buatan; tetap atau sementara; dengan air yang tergenang atau mengalir, tawar, payau atau asin; termasuk wilayah perairan laut yang kedalamannya tidak lebih dari enam meter pada waktu air surut. ${ }^{20}$ Dari definisi tersebut sebenarnya wilayah pantai yang kurang dari kedalaman 6 meter masih dianggap termasuk dalam definisi ini. Mengenai sejauhmana wilayah berlakunya masih perlu diperinci lagi mana yang termasuk daftar dalam konvensi ini.

Ekosistem lahan basah merupakan ekosistem peralihan antara ekosistem perairan (aquatic) dan ekosistem daratan (terrestrial), adanya dominasi rezim air dan adanya tanaman (hidrofita) yang mempunyai daya adaptasi yang baik terhadap kondisi lahan yang senantiasa jenuh (tergenang) air, secara fisik berupa daerah-daerah seperti yang didefinisikan dalam Pasal 1 tersebut. ${ }^{21}$ Pemahaman

\footnotetext{
Ramsar Convention Secretariat, Op.cit., hlm.8.

Koesnadi Hardjasoemantri, 1993, Hukum Perlindungan Lingkungan Konservasi Sumber Daya Alam Hayati dan Ekosistemnya, Edisi Pertama, Cetakan Kedua, Gadjah Mada University Press, Yogyakarta, hlm.147.

Maryatul Qiptiyah, 2008, Struktur Komunitas Burung Pantai Migran di Berbagai Tipe Habitat Kawasan Lahan Basah Tambaksari, Sayung, Demak, Tesis, Program Studi Ilmu Kehutanan, Sekolah Pascasarjana UGM, hlm.13.

Ramsar Convention Secretariat, Loc.cit.

William J. Mitsch, et al., 2015, Wetlands, Fifth Edition, Wiley, hlm.17.

20 James Gordon Nelson, 1997, National Parks and Protected Areas: Keystones to Conservation and Sustainable Development, Springer, hlm.269. Lihat Pasal 1 ayat (1) Konvensi Ramsar yang berbunyi: "area of marsh, fen, peatland or water, whether natural or artificial, permanent or temporary, with water that is static or flowing, fresh, blockish or silt, including areas of marine water the depth of which at low tide does not exceed six meters".

21 C. Max Finlayson, et al., 1995, Classification and Inventory of The World's Wetlands, Springer, hlm.41.
} 
karakteristik tentang ekosistem lahan basah mutlak untuk diketahui agar pemanfaatan ekosistem ini tetap memperhatikan sifat dan karakternya, sehingga dampak ekologis dapat diminimalisasi. Ekosistem lahan basah dapat dikelompokkan menjadi ekosistem air tawar dan ekosistem estuarin (muara). Ekosistem air tawar dapat berupa air yang tenang misalnya rawa, empang, kolam maupun air mengalir yaitu sungai. Ekosistem estuarin dipengaruhi pasang surut air laut, misalnya rawa payau, hutan mangrove, dan laguna. Selain itu, ekosistem lahan basah dapat dikelompokkan menjadi lahan basah alami dan buatan, kemudian dikelompokkan menjadi tiga kategori yaitu lahan basah perairan/laut (marine and coastal wetlands), lahan basah daratan (inland wetlands), dan lahan basah buatan manusia (human-made wetlands). ${ }^{22}$

Menurut Konvensi Ramsar, ekosistem lahan basah diklasifikasikan menjadi lima kawasan, yai$\mathrm{tu}:^{23}$

1) Kawasan laut (marine): meliputi kelompok lahan basah yang berair asin, pesisir dan laguna (coastal wetlands including coastal lagoons), termasuk pantai berbatu (rocky shores), terumbu karang (coral reefs) dan padang lamun (seagrass beds);

2) Kawasan muara (estuarine): muara sungai, delta (deltas), rawa pasang surut yang berair payau (tidal marshes) dan hutan bakau (mangrove swamps);

3) Kawasan rawa (palustrin): meliputi daerah yang bersifat rawa (berair tergenang atau lembab), misalnya hutan rawa air tawar, hutan rawa gambut dan rawa rumput ("marshy"marshes, swamps and bogs);

4) Kawasan danau (lakustrin): meliputi semua lahan basah yang berhubungan dengan danau (wetlands associated with lakes) dan biasanya berair tawar;

5) Kawasan sungai (riverin): meliputi lahan basah yang terdapat di sepanjang sungai atau perairan yang mengalir (wetlands along rivers and streams).

Pasal 2 ayat (2) menyatakan bahwa perlunya dibuat pilihan lahan basah untuk dimasukkan dalam suatu daftar yang didasarkan pentingnya makna internasional yang terkandung baik dari sudut ekologi, botani, zoologi, limnologi, dan hidrologi. Pasal 2 ayat (4) menyatakan bahwa setiap negara anggota memiliki kewajiban untuk menetapkan sekurang-kurangnya sebidang lahan basah untuk dimasukkan dalam sebuah daftar lahan basah yang mempunyai makna internasional, pada waktu negara tersebut menandatangani atau meratifikasi atau tunduk pada konvensi. ${ }^{24}$ Lahan basah dengan makna internasional bagi burung unggas dalam musim apa pun, perlu dimasukkan. Kendati demikian tidak semua jenis lahan basah layak dimasukkan dalam daftar konvensi. ${ }^{25}$

Setiap negara anggota juga harus membuat beberapa dokumen yang memperlihatkan secara jelas mengapa lahan basah tersebut penting untuk dapat dimasukkan ke dalam daftar sebagai lahan basah yang memiliki kepentingan secara internasional, dengan menunjukkan adanya rencana pengelolaan lahan basah. Pasal 3 Konvensi Ramsar menentukan bahwa negara anggota merumuskan dan melaksanakan perencanaan sedemikian rupa sehingga mengembangkan konservasi lahan basah yang termasuk dalam daftar Situs Ramsar, dan sedapat mungkin mengembangkan penggunaan lahan basah yang ada di wilayah negaranya secara bijak (wise use). ${ }^{26}$ Prinsip yang paling fundamental

\footnotetext{
Direktorat Kawasan Konservasi dan Bina Hutan Lindung, Op.cit., hlm.32-33. Lihat Ramsar Wetland Type Classification, Loc.cit. D.A. Scott, et al., 1995, "Classification and Inventory of Wetlands: A Global Overview", Vegetatio, Vol.118, No.1/2, hlm.10.

"Each contracting party shall designate at least one wetland to be included in the list when signing this Convention or when depositing its instrumen of ratification or accession, as provided in Article 9".

Untung Iskandar, 1999, Kerjasama Internasional Menuju Pengelolaan Hutan Lestari, Bigraf Publishing, Yogyakarta, hlm.183.

Abdul Haseeb Ansari, et al., 2011, "Ramsar Convention and Convention on Biological Diversity as Mechanism for Promoting Biodiversity Conservation of Malaysian Wetlands", Journal of Applied Sciences Research, Vol.7,No. 13, hlm.2386.
} 
dari Konvensi Ramsar 1971 yaitu wise use, yang berarti pemanfaatan lahan basah secara bijaksana. ${ }^{27}$ Pemanfaatan lahan basah secara bijak didefinisikan sebagai "pemanfaatan lahan basah secara berkelanjutan dengan mempertimbangkan faktor keseimbangan antara kebutuhan manusia dan alam, dengan tetap menjaga kelestarian dari sifat alami ekosistem lahan basah". ${ }^{28}$

Terdapat beberapa kriteria pengidentifikasian suatu kawasan lahan basah yang memiliki nilai universal penting untuk tercatat ke dalam Daftar Situs Ramsar (Ramsar Listed Sites), yaitu: ${ }^{29}$

1) Keterwakilan, langka atau unik; $;^{30}$

2) Konservasi keanekaragaman hayati; $; 1$

3) Kriteria khusus burung air (water birds); ${ }^{32}$

4) Kriteria khusus ikan; ${ }^{33}$ dan

5) Kriteria khusus untuk jenis-jenis yang lain. $^{34}$

Selanjutnya Pasal 4 konvensi menyebutkan bahwa setiap negara anggota diwajibkan untuk mengembangkan lahan basah serta memperhatikan keberadaan burung unggas dengan mendirikan cagar alam di lahan basah dengan tidak memperhatikan apakah lahan tersebut termasuk dalam daftar Situs Ramsar ataupun tidak. Negara diwajibkan pula untuk menyediakan penjagaan dan pemantauan kawasan yang memadai.
Pasal 6 Konvensi Ramsar menyatakan bahwa perlunya ditetapkan konferensi yang teratur dan negara anggota diwajibkan hadir, serta diharapkan dapat memberi rekomendasi mengenai konservasi, pengelolaan serta pengaturan secara bijaksana lahan basah beserta flora dan faunanya. Negara anggota menjamin bahwa rekomendasi tersebut akan memperoleh perhatian. Pasal 9 ayat (2) menyebutkan mengenai tata cara bagaimana negaranegara dapat tergabung dalam konvensi ini. Tata cara ini terbagi dalam 3 hal yaitu: Penandatanganan tanpa syarat bagi pengesahan; Penandatanganan sebagai dasar pengesahan yang selanjutnya disahkan; dan Tambahan (Accession). Kriteria menetapkan pilihan lahan basah telah dibuat dan khusus pada lahan basah yang memiliki makna internasional telah diidentifikasi dan dilampirkan dalam Rekomendasi Regina. Ditetapkan pula petunjuk mengenai penggunaan secara bijak (wise use) dalam pengembangan lahan basah.

Kawasan lahan basah berupa laut (marine), muara (estuarine), rawa (palustrin), danau (lakustrin), dan sungai (riverin) tersebut memiliki nilai universal penting untuk tercatat ke dalam Daftar Situs Ramsar yang dari segi jumlah terus mengalami peningkatan. Pada tahun 2011, terdapat 1.971 Situs Ramsar dengan luas mencapai 191 juta hektar yang didaftarkan oleh 160 Negara yang

Vishnu N. Prahalad, Lorne K. Kriwoken, 2010, "Implementation of the Ramsar Convention on Wetlands in Tasmania, Australia", Journal of International Wildlife Law and Policy, Vol.13, No.3, hlm.208.

28 Peter Dauvergene, 2009, Historical Dictionary of Environmentalism, The Scarecrow Press, UK, hlm.40-41.

29 IUCN-The World Conservation Union, "International Agreements and Programmes", Parks, Vol.12, No.3, 2002, hlm.42.

30 Kriteria Keterwakilan, Langka atau Unik yakni lahan basah menjadi contoh keterwakilan, langka atau unik dari tipe lahan basah alami atau yang mendekati alami sesuai karakteristik wilayah biogegografinya (Kriteria 1).

31 Kriteria Konservasi Keanekaragaman Hayati, yaitu lahan basah itu mendukung spesies rentan, langka atau hampir langka, atau ekologi komunitas yang terancam (Kriteria 2), lahan basah tersebut mendukung populasi jenis tumbuhan dan/atau hewan yang penting bagi pemeliharaan keanekaragaman hayati di wilayah biogeografi yang sesuai (Kriteria 3), dan lahan basah tersebut mendukung jenis tumbuhan dan/atau hewan yang kritis dalam siklus hidup atau merupakan tempat perlindungan bagi jenis-jenis tersebut saat melewati masa kritis dalam siklus hidupnya (Kriteria 4$)$

32 Kriteria khusus burung air (water birds), yakni lahan basah tersebut secara teratur mendukung/dihuni oleh 20.000 atau lebih jenis burung air (Kriteria 5), dan lahan basah tersebut secara teratur mendukung/dihuni oleh individu-individu dari satu spesies atau sub-spesies burung air hingga $1 \%$ dari total populasi spesies/sub-spesies burung air tersebut (Kriteria 6).

33 Kriteria khusus ikan, yaitu lahan basah tersebut mendukung/dihuni oleh proporsi yang nyata dari spesies/sub-spesies/famili ikan-ikan asli, perkembangan sejarah kehidupan dan interaksi satu sama lainnya sehingga menunjukkan adanya nilai-nilai atau kontribusi penting dari lahan basah tersebut terhadap keanekaragaman hayati (Kriteria 7), dan lahan basah itu menjadi sumber makanan yang penting bagi ikan, tempat berpijah dan asuhan dan/atau sebagai jalur migrasi untuk stok ikan yang berada di lahan basah atau tempat lain di luar lahan basah tersebut (Kriteria 8).

34 Kriteria khusus untuk jenis-jenis yang lain, yakni lahan basah tersebut secara teratur mendukung 1\% dari individu-individu dari satu spesies/ sub-spesies bukan burung yang bergantung pada lahan basah (Kriteria 9). 
menjadi anggota Konvensi. ${ }^{35}$ Jumlah Situs Ramsar terus mengalami peningkatan. Pada tahun $2018^{36}$ tercatat, sudah ada sebanyak 2.303 Situs Ramsar dengan total luas wilayah mencapai 228 juta hektar yang telah didaftarkan oleh 169 Negara anggota Konvensi dari enam Ramsar Region, yakni Afrika, Asia, Eropa, Amerika Latin dan Karibia, Amerika Utara, dan Oceania. ${ }^{37}$

Indonesia yang merupakan negara kepulauan dan wilayahnya didominasi oleh lahan basah, ikut menjadi anggota Konvensi Ramsar dan mulai terikat sejak 8 Agustus tahun 1992. Lahan basah di Indonesia didominasi oleh lahan gambut yang meraih predikat terluas di Asia Tenggara. ${ }^{38}$ Keikutsertaan Indonesia dalam Konvensi Ramsar secara formal tertuang dalam Keputusan Presiden (Keppres) Nomor 48 Tahun $1991^{39}$ pada tanggal 19 Oktober 1991, dengan mengajukan Taman Nasional Berbak di Provinsi Jambi sebagai Situs Ramsar. Saat ini Indonesia memiliki 7 situs Ramsar, dengan luas mencapai 1.424.976 hektar. Ketujuh situs ini diantaranya, Taman Nasional (TN) Berbak seluas 162.700 hektar; TN Danau Sentarum (Kalimantan Barat) seluas 132.000 hektar; TN Wasur (Papua) seluas 413.810 hektar; TN Sembilang (Sumatera Selatan) seluas 202.896 hektar; TN Rawa AopaWatumohai (Sulawesi Tenggara) seluas 105.194 hektar; Suaka Margasatwa Pulau Rambut (DKI Jakarta) seluas 90 hektar; dan TN Tanjung Puting (Kalimantan Tengah) seluas 408.286 hektar. ${ }^{40}$

\section{Implementasi Konvensi Ramsar 1971 di Indonesia \\ Indonesia meratifikasi Konvensi Ramsar} berdasarkan Keputusan Presiden (Keppres) Nomor 48 Tahun 1991, dengan mendaftarkan Taman Nasional Berbak sebagai Situs Ramsar yang merupakan lahan basah yang memiliki makna internasional. ${ }^{41}$ Melalui Keppres tersebut, pemerintah menunjukkan komitmennya dalam mengimplementasikan ketentuan-ketentuan di dalam Konvensi Ramsar. Pemerintah telah membuat peraturan pelaksana (implementing legislation) melalui SK Menteri Kehutanan No.226/KptsVI/94 Tahun 1994. Pemerintah juga telah membuat Komite Nasional Pengelolaan Ekosistem Lahan Basah, sebagai wadah untuk memformulasikan dan mengimplementasikan konsep dan program pengelolaan lahan basah di Indonesia. Komite ini dibantu kelompok kerja yang dibentuk melalui SK Direktur Jenderal PHKA No.30/IV-SET/2014.

Pengelolaan lahan basah mengacu pada Strategi Nasional dan Rencana Aksi Pengelolaan Lahan Basah yang disusun berdasarkan lima pilar, yaitu Konservasi, Rehabilitasi, dan Pemanfaatan yang Bijaksana; Azas Manfaat dan Prioritas; Berbasis Masyarakat; Pengelolaan Secara Terpadu; dan Tata Laksana yang Baik (Good Governance). ${ }^{42}$ Indonesia terikat pada kewajiban dan komitmen penyelamatan lahan basah melalui upaya konservasi dan pemanfaatannya secara bijaksana, dan telah mendaftarkan kawasan lahan basah sebagai Situs Ramsar.

\footnotetext{
Robert P. Brooks, et.al., "Ramsar Protected Wetlands of International Importance as Habitats for Otters", IUCN Otter Spec. Group Bull, Vol.28, 2011, hlm.48.

Lihat https://www.ramsar.org.

C. Max Finlayson, et.al., Op.cit., hlm.182.

Mitsuru Osaki, et al., 2016, Tropical Peatland Ecosystems, Springer, Japan, hlm.564.

39 Lihat Keputusan Presiden (Keppres) Republik Indonesia Nomor 48 Tahun 1991 tentang Pengesahan Conventions on Wetlands of International Importance, Especially as Waterfowl Habitat.

40 Direktorat Kawasan Konservasi dan Bina Hutan Lindung, Op.cit., hlm.6.

1 Pasal 2 ayat 4 Konvensi Ramsar mewajibkan setiap anggota menunjuk satu lahan basah untuk dimasukkan dalam daftar Wetlands of International Importance saat penandatanganan Konvensi.

42 Komite Nasional Pengelolaan Ekosistem Lahan Basah, 2004, Strategi Nasional dan Rencana Aksi Pengelolaan Lahan Basah Indonesia, Kementerian Lingkungan Hidup, hlm.58.
} 
Tabel 1. Struktur Keanggotaan Indonesia dalam Konvensi Ramsar ${ }^{43}$

\begin{tabular}{lll}
\hline No & Jabatan & Designation \\
\hline 1. & $\begin{array}{l}\text { Direktur Jenderal Konservasi Sumber Daya } \\
\text { Alam dan Ekosistem }\end{array}$ & Administrative Authority \\
\hline 2. & $\begin{array}{l}\text { Direktur Bina Pengelolaan Ekosistem } \\
\text { Esensial }\end{array}$ & National Focal Point (NFP) \\
\hline 3. & $\begin{array}{l}\text { Direktur Konservasi Keanekaragaman } \\
\text { Hayati }\end{array}$ & $\begin{array}{l}\text { Communication, Education, Participation and } \\
\text { Awareness (CEPA) NFP (Pemerintah) }\end{array}$ \\
\hline 4. & $\begin{array}{l}\text { Kepala Subdit Konservasi Lahan Basah } \\
\text { dan Taman Kehati }\end{array}$ & $\begin{array}{l}\text { Daily Contact dan anggota Steering Committee } \\
\text { Ramsar Regional Center-East Asia (RRC-EA) }\end{array}$ \\
\hline 5. & Peneliti, Puslit Limnologi LIPI & $\begin{array}{l}\text { Anggota Scientific and Technical Review Panel } \\
\text { (STRP) NFP }\end{array}$ \\
\hline 6. & Direktur Wetlands International Indonesia & CEPA NFP (LSM) \\
\hline
\end{tabular}

Sumber: Direktorat Kawasan Konservasi dan Bina Hutan Lindung, 2015.

Sebagai anggota Konvensi Ramsar, Indonesia terikat pada prinsip pacta sunt servanda, yakni negara anggota harus melaksanakan perjanjian internasional dengan itikad baik (good faith). Dalam praktiknya, implementasi sebuah kewajiban dan komitmen internasional dapat dilihat dari dua perspektif, yakni perspektif perundang-undangan nasional dan praktik dalam hukum nasionalnya. ${ }^{44}$ Jika dilihat dari perspektif perundang-undangan, Indonesia telah mengadvokasi prinsip good faith dalam mengimplementasikan setiap kewajiban di dalam perjanjian internasional, seperti dalam ketentuan Pasal 4 UU Perjanjian Internasional, yang juga meminta partisipasi aktif dari negara untuk melaksanakan ketentuan perjanjian internasional yang telah diratifikasi secara konkrit. ${ }^{45}$

Konvensi Ramsar telah ditransformasikan ke dalam hukum nasional. Substansi Konvensi Ramsar telah dicakup dalam beberapa peraturan yang mendasarkan pada konsep ilmiah yakni konservasi ekosistem alami termasuk lahan basah. ${ }^{46}$ UndangUndang Nomor 5 Tahun 1990 tentang Konservasi Sumberdaya Alam dan Ekosistemnya ${ }^{47}$ serta Undang-Undang Nomor 32 Tahun 2009 tentang Perlindungan dan Pengelolaan Lingkungan Hidup ${ }^{48}$ secara kontekstual berbicara keseluruhan ekosistem lahan basah yang penting untuk dilindungi.

Pemerintah telah menetapkan UndangUndang Nomor 26 Tahun 2007 Tentang Penataan Ruang yang mengelompokkan kawasan lindung menjadi kawasan suaka alam dan kawasan pelestarian alam, cagar budaya, dan kawasan lindung lainnya, seperti taman buru, cagar biosfer, kawasan perlindungan plasma nutfah, kawasan pengungsian satwa, dan terumbu karang. Peraturan Pemerintah (PP) Nomor 26 Tahun 2008 Tentang

43 Direktorat Kawasan Konservasi dan Bina Hutan Lindung, Op.cit., hlm.27.

44 Agustina Merdekawati, et al., 2016, "Analysis on Indonesia’s fulfillment of Obligations Rising from International Treaties”, Jurnal Mimbar Hukum, Vol.28, No.3, hlm.500.

45 Pasal 4 ayat (1) dan (2) Undang-Undang Nomor 24 Tahun 2000 tentang Perjanjian Internasional

46 Wawancara Penulis dengan Hans Nico Sinaga, Kepala Seksi Pemolaan Ekosistem Esensial, Direktorat Bina Pemolaan Ekosistem Esensial, Kementerian Lingkungan Hidup dan Kehutanan, tanggal 2 Mei 2017.

47 Undang-undang ini mengatur hal-hal yang berkenaan dengan usaha perlindungan sistem penyangga, pengawetan keanekaragaman tumbuhan dan satwa beserta ekosistemnya. Menurut Pasal 11, pengawetan keanekaragaman tumbuhan dan satwa beserta ekosistemnya dilaksanakan melalui kegiatan (a) pengawetan keanekaragaman tumbuhan dan satwa beserta ekosistemnya; (b) pengawetan jenis tumbuhan dan satwa. Maksud dari pengawetan yakni usaha untuk menjaga agar keanekaragaman jenis tumbuhan dan satwa beserta ekosistemnya tidak punah.

48 Pasal 57 ayat (1) huruf a undang-undang ini menjelaskan bahwa pemeliharaan lingkungan hidup dilakukan melalui upaya konservasi sumber daya alam, yang meliputi, antara lain, konservasi sumber daya air, ekosistem hutan, ekosistem pesisir dan laut, energi, ekosistem lahan gambut, dan ekosistem karst. Pemeliharaan lingkungan hidup yang dimaksud adalah upaya yang dilakukan untuk menjaga pelestarian fungsi lingkungan hidup dan mencegah terjadinya penurunan atau kerusakan lingkungan hidup yang disebabkan oleh perbuatan manusia. 
Rencana Tata Ruang Wilayah Nasional telah mencantumkan Ramsar ke dalam ruang lingkup kawasan lindung, bersama dengan cagar biosfer, dan warisan dunia. Kriteria kawasan lindung yang menjadi Situs Ramsar, dan pelaksanaan prioritas pengelolaan dan pemulihan terhadap dua Situs Ramsar yang masuk dalam peraturan ini, yakni TN Berbak dan TN Danau Sentarum.

Dalam Peraturan Presiden (Perpres) Nomor 3 Tahun 2012 Tentang Rencana Tata Ruang Pulau Kalimantan, memberikan pengelompokkan yang sama terhadap kawasan lindung lainnya, yakni Ramsar, cagar biosfer, taman buru, terumbu karang, dan koridor ekosistem. Perpres ini secara detail menyebutkan pengelolaan Ramsar berada di dalam pengelolaan kawasan lindung nasional. ${ }^{49}$ Hal ini ditunjukkan dengan tujuannya yang ingin mempertahankan dan melestarikan sistem tata air dan ekosistem alamiah pada kawasan Ramsar. Kawasan Situs Ramsar yang masuk dalam Perpres ini adalah Situs Ramsar TN Danau Sentarum.

Penulis juga melihat ketentuan di dalam PP Nomor 28 Tahun 2011 juncto PP Nomor 108 Tahun 2015 Tentang Pengelolaan Kawasan Suaka Alam dan Kawasan Pelestarian Alam, yang menyatakan bahwa Pemerintah dapat mengusulkan suatu Kawasan Suaka Alam (suaka margasatwa dan cagar alam) atau Kawasan Pelestarian Alam (taman nasional, taman hutan raya, dan taman wisata alam) sebagai warisan alam dunia (world heritage), cagar biosfer, atau sebagai perlindungan tempat migrasi satwa internasional atau situs Ramsar (Ramsar site) kepada lembaga internasional yang berwenang untuk ditetapkan sesuai dengan kriteria yang ditentukan oleh lembaga internasional yang bersangkutan. Peraturan tersebut telah mengakomodasi Situs Ramsar Suaka Margasatwa Pulau Rambut yang berstatus sebagai Kawasan Suaka Alam.

Keppres Nomor 32 Tahun 1990 tentang Pengelolaan Kawasan Lindung, mendefinisikan kawasan lindung sebagai kawasan yang ditetapkan dengan fungsi utama melindungi kelestarian lingkungan hidup yang mencakup sumber alam, sumber daya buatan dan nilai sejarah serta budaya bangsa guna kepentingan pembangunan berkelanjutan. Keppres ini telah memberikan pengelompokkan kawasan lindung yang selaras dengan definisi dalam ketentuan Pasal 1 Konvensi Ramsar, yakni lahan basah adalah daerah-daerah rawa, payau, lahan gambut dan perairan, baik alami maupun buatan, tetap maupun sementara, dengan perairannya yang tergenang ataupun mengalir, tawar, payau maupun asin, termasuk wilayah perairan laut yang kedalamannya tidak lebih dari enam meter pada waktu surut.

Kemudian PP Nomor 71 Tahun 2014 juncto PP Nomor 57 Tahun 2016 tentang Perlindungan dan Pengelolaan Ekosistem Gambut memperlihatkan bahwa pengelolaan lahan basah harus dilaksanakan secara menyeluruh dan terpadu, untuk menjamin keberadaan, pemanfaatan secara bijaksana, ketersediaan, dan kesinambungan sumber daya lahan basah agar tetap lestari. Hal itu selaras dengan ketentuan Pasal 3 Konvensi Ramsar, bahwa para anggota merumuskan dan melaksanakan perencanaannya dalam rangka meningkatkan pelestarian dan pemanfaatan lahan basah secara bijaksana.

Dalam konteks perlindungan dan pengelolaan ekosistem lahan basah seperti gambut, memerlukan upaya sistematis dan terpadu untuk melestarikan fungsi dan mencegah terjadinya kerusakan, meliputi perencanaan, pemanfaatan, pengendalian, pemeliharaan, pengawasan, dan penegakan hukum. Tujuannya untuk melindungi gambut dari kerusakan, dan untuk mengendalikan pemanfaatannya secara bijaksana (wise use). Ekosistem gambut dikenal sebagai salah satu ekosistem yang unik, tetapi rapuh dan sensitif terhadap pengembangan.

49 Pasal 40 huruf f menjelaskan bahwa strategi operasionalisasi perwujudan kawasan lindung nasional terdiri atas strategi operasionalisasi perwujudan kawasan lindung lainnya. Pasal 46 ayat (1) huruf a menjelaskan bahwa kawasan lindung lainnya sebagaimana dimaksud dalam Pasal 40 huruf f adalah ramsar. Pasal 46 ayat (2) huruf a dan ayat (3) menjelaskan bahwa strategi operasionalisasi perwujudan pengelolaan kawasan lindung lainnya dengan mempertahankan dan melestarikan sistem tata air dan ekosistem alamiah pada kawasan ramsar yang dilakukan di kawasan ramsar Danau Sentarum. 
Tabel 2.

\section{Luasan Gambut di Taman Nasional Tanjung Puting ${ }^{50}$}

\begin{tabular}{lllllll}
\hline No & Nama Resort & Luasan Resort & Mineral Soil & \multicolumn{3}{l}{ Gambut } \\
\cline { 3 - 7 } & & & Hektar & $(\%)$ & Hektar & $(\%)$ \\
\hline $\mathbf{1}$ & Sungai Kole & $8,823.13$ & $8,823.13$ & 100.00 & - & \\
\hline $\mathbf{2}$ & Pembuang Hulu & $22,693.62$ & $22,693.62$ & 100.00 & - & \\
\hline $\mathbf{3}$ & Telaga Pulang & $27,532.70$ & $15,938.70$ & 57.89 & $11,594.00$ & 42.11 \\
\hline $\mathbf{4}$ & Pondok Ambung & $5,927.33$ & $5,927.33$ & 100.00 & - & \\
\hline $\mathbf{5}$ & Baung & $41,124.95$ & $14,902.96$ & 36.24 & $26,222.00$ & 63.76 \\
\hline $\mathbf{6}$ & Tanjung Rengas & $57,145.93$ & $23,992.93$ & 41.99 & $33,153.00$ & 58.01 \\
\hline $\mathbf{7}$ & Sungai Perlu & $49,139.00$ & $42,610.00$ & 86.71 & $6,529.00$ & 13.29 \\
\hline $\mathbf{8}$ & Camp Leakey & $26,126.42$ & $14,617.42$ & 55.95 & $11,509.00$ & 44.05 \\
\hline $\mathbf{9}$ & Pesalat & $20,718.91$ & $14,501.91$ & 69.99 & $6,217.00$ & 30.01 \\
\hline $\mathbf{1 0}$ & Teluk Pulai & $98,691.71$ & $29,137.72$ & 29.52 & $69,554.00$ & 70.48 \\
\hline $\mathbf{1 1}$ & Sungai Cabang & $50,363.81$ & $32,304.82$ & 64.14 & $18,059.00$ & 35.86 \\
\hline & Total & $\mathbf{4 0 8 , 2 8 7 . 5 1}$ & $\mathbf{2 2 5 , 4 5 0 . 5 4}$ & $\mathbf{5 5 . 2 2}$ & $\mathbf{1 8 2 , 8 3 7 . 0 0}$ & $\mathbf{4 4 . 7 8}$ \\
\hline
\end{tabular}

Sumber: Dian Novita, 2016.

Taman Nasional Tanjung Puting yang telah ditetapkan sebagai Situs Ramsar ketujuh di Indonesia ${ }^{51}$, mengandung sumber daya hutan lahan basah yang bernilai tinggi yang didominasi hutan rawa gambut. Situs Ramsar ini termasuk tipe lahan basah perairan/laut (marine and coastal wetlands), berupa perairan estuarin (muara), pantai intertidal berlumpur, berpasir atau bergaram, dan lahan basah berhutan (bakau dan rawa). Hutan rawa gambut, hutan rawa, dan hutan nipah mencapai $40 \%$ dari luas kawasan. ${ }^{52}$

Meski Tanjung Puting telah ditetapkan sebagai Situs Ramsar, dalam pelaksanaannya masih ditemukan beberapa permasalahan. Masalah pertama adalah sosialisasi yang belum dilakukan secara intensif dan luas kepada stakeholders terkait. Sosialisasi menjadi penting karena pengetahuan dan pemahaman atas Ramsar tidak dimiliki oleh seluruh pegawai Balai Taman Nasional Tanjung Puting maupun oleh pemerintah daerah, masyarakat, dan mitra, yakni LSM yang telah membantu taman nasional dalam upaya konservasi dan rehabilitasi kawasan.

Pihak mitra taman nasional belum mendapatkan sosialisasi langsung, saat ingin membahas pencalonan ataupun setelah Tanjung Puting ditetapkan sebagai Situs Ramsar. Sehingga pihak mitra dalam hal ini LSM, tidak mengerti seberapa penting suatu kawasan lahan basah, bagaimana cara melindunginya, dan apa peran mitra dalam pengelolaan lahan basah berupa Situs Ramsar tersebut. ${ }^{53}$ Menurut Insan Kamil, ia tidak mengetahui secara spesifik mengenai Konvensi Ramsar karena sosialisasinya yang masih kurang, sehingga belum mengetahui dampaknya terhadap Tanjung Puting setelah ditetapkan sebagai Situs Ramsar. Sosialisasi dari Konvensi Ramsar sangat penting dilakukan kepada aparat pemerintah, khususnya yang berasal dari instansi yang terkait, dan terhadap LSM terutama yang menjadi mitra dari pemerintah, serta masyarakat, agar tercipta sense of belonging, ownership, dan senses of pride. ${ }^{54}$

50 Dian Novita, loc.cit.

51 Ditetapkan menjadi Situs Ramsar Nomor 2192.

52 Balai Taman Nasional Tanjung Puting, 1999, Rencana Pengelolaan Taman Nasional Tanjung Puting (1999-2024) Buku II (Data, Proyeksi, dan Analisis), Kumai, hlm.261.

53 Wawancara Penulis dengan Fajar Dewanto, Field Director, Orangutan Foundation International (OFI), dan Basuki Budi Santoso, Borneo Manager, Friends of the National Park Foundation (FNPF), tanggal 27 Maret 2017, serta Ade Soeharso, Manager, Orangutan Foundation-UK (OF-UK), tanggal 3 April 2017.

54 Wawancara Penulis dengan Insan Kamil, Kepala SPTN Wilayah III, Balai Taman Nasional Tanjung Puting, tanggal 10 April 2017 , dan Alue Dohong, Deputi Konstruksi, Operasi, dan Pemeliharaan, Badan Restorasi Gambut, tanggal 3 Mei 2017. 
Tabel 3.

Rencana Kerja Tahunan (RKT) Taman Nasional Tanjung Puting 2015-201755

\begin{tabular}{llrrr}
\hline \multirow{2}{*}{ No } & \multirow{2}{*}{ Program Kerja } & \multicolumn{3}{c}{ Tahun } \\
\cline { 2 - 4 } 1 & Peningkatan kapasitas SDM & 2015 & 2016 & 2017 \\
\hline 2 & Pembinaan dan pemberdayaan masyarakat desa penyangga & $\sqrt{ }$ & $\sqrt{ }$ \\
\hline 3 & Pengembangan usaha ekonomi masyarakat desa penyangga & $\sqrt{ }$ & $X$ & $\sqrt{ }$ \\
\hline 4 & Pembentukan kader konservasi & $\sqrt{ }$ & $X$ & $\sqrt{ }$ \\
\hline 5 & Monitoring populasi satwa liar & $\sqrt{ }$ & $\sqrt{ }$ & $\sqrt{ }$ \\
\hline 6 & Monitoring populasi penyu dan keanekaragaman jenis ikan & $\sqrt{ }$ & $\sqrt{ }$ & $\sqrt{ }$ \\
\hline 7 & Pembinaan populasi satwa liar dan pengawetan jenis keanekaragaman hayati & $\mathrm{V}$ & $\mathrm{X}$ & $\sqrt{ }$ \\
\hline 8 & Patroli bersama masyarakat & $\sqrt{ }$ & $\mathrm{X}$ & $\sqrt{ }$ \\
\hline 9 & Pemadaman dan penanganan pasca kebakaran & $\sqrt{ }$ & $X$ & $X$ \\
\hline 10 & Penyadartahuan dan promosi pencegahan kebakaran & $\sqrt{ }$ & $X$ & $X$ \\
\hline 11 & Pencegahan kebakaran hutan & $X$ & $\sqrt{ }$ & $X$ \\
\hline 12 & Pengamanan kawasan hutan & $\sqrt{ }$ & $\sqrt{ }$ & $X$ \\
\hline 13 & Rencana pemulihan ekosistem & $X$ & $X$ & $\sqrt{ }$ \\
\hline 14 & Peningkatan sarana prasarana perlindungan dan pengamanan taman nasional & $X$ & $\sqrt{ }$ & $\sqrt{ }$ \\
\hline 15 & Pengamanan dan pengendalian peredaran hasil hutan & $X$ & $\sqrt{ }$ & $X$ \\
\hline 16 & Pembangunan/pengembangan database spasial & $\sqrt{ }$ & $\sqrt{ }$ & $\sqrt{ }$ \\
\hline 17 & Penyusunan desain tapak wisata alam & $\sqrt{ }$ & $\sqrt{ }$ & $\sqrt{ }$ \\
\hline 18 & Pembangunan dan pengembangan sarana prasarana wisata alam & $\sqrt{ }$ & $\sqrt{ }$ & $\sqrt{ }$ \\
\hline
\end{tabular}

Sumber: Balai Taman Nasional Tanjung Putting, 2015-2017.

2015 hingga 2017. Program kerja yang telah ada belum secara spesifik mengenai Ramsar. Setelah ditetapkan sebagai Situs Ramsar, sudah menjadi kewajiban dalam pengelolaannya harus sesuai dengan kaidah-kaidah Konvensi Ramsar. Salah satunya, dengan memasukan komitmen konservasi lahan basah dalam rencana pengelolaan, kebijakan dan pendidikan masyarakat sekitar kawasan.

Ketiga, masalah pengawasan dan koordinasi antar institusi yang masih rendah, serta terbatasnya SDM dan anggaran, menimbulkan dampak yang cukup signifikan terhadap perlindungan Situs Ramsar Tanjung Puting. Basuki Budi Santoso, belum melihat ada tindakan serius yang secara spesifik menangani perlindungan gambut yang sering sekali terbakar. ${ }^{57}$ Beberapa area yang sebelumnya bekas aktivitas logging yang sebagian besar gambut, dan telah terdapat kanal-kanal sebagai sarana untuk pengangkut kayu yang dilindungi seperti Ramin,
Kedua, masalah sumber daya manusia (SDM), dan anggaran. Perlindungan Situs Ramsar Tanjung Puting belum didukung oleh SDM, anggaran, dan sarana prasarana yang memadai, sehingga implementasinya belum berjalan dengan baik. ${ }^{57}$ Padahal, Tanjung Puting telah memiliki rencana pengelolaan sebagai panduan yang diperlukan untuk pengelolaan kawasan. Dalam Buku Rencana Pengelolaan Taman Nasional Tanjung Puting Volume II, perlindungan dan pengelolaan lahan basah mengacu kepada perjanjian internasional yang berhubungan dengan pengelolaan kawasan dan sumber daya lahan basah yang telah diratifikasi oleh Pemerintah, yaitu Konvensi Ramsar. Tujuannya untuk menjaga pelestarian lahan basah beserta flora dan fauna di dalamnya.

Namun, perlindungan Situs Ramsar belum menjadi sebuah program kerja di dalam RKT Balai Taman Nasional Tanjung Puting mulai tahun

\footnotetext{
55 Penulis merangkum Rencana Kerja Balai Taman Nasional Tanjung Puting Tahun Anggaran 2015, 2016, dan 2017 menjadi satu tabel Rencana Kerja Tahunan (RKT) Balai Taman Nasional Tanjung Puting 2015-2017.

Wawancara Penulis dengan Budi Suriansyah, Kepala SPTN Wilayah II, tanggal 13 April 2017.

57 Wawancara Penulis dengan Basuki Budi Santoso, Borneo Manager, Friends of the National Park Foundation (FNPF), tanggal 27 Maret 2017.
} 
Ulin, Meranti, telah berdampak pada menurunnya fungsi ekologi gambut sebagai penyimpan air, dan merusak proses hidrologi yang berakibat menurunnya muka air. Kondisinya sudah sangat terbuka, dan menjadi titik langganan kebakaran sebelum merambat ke daerah lain.

Data Orangutan Foundation International (OFI) mencatat, jumlah titik panas di Tanjung Puting tahun 2015 sebanyak 2.365 hotspot, yang merupakan jumlah terbanyak dalam kurun waktu 10 tahun terakhir, setelah sebelumnya terjadi di tahun 2006 dengan jumlah 1.687 hotspot. Perkiraan luasan area yang terbakar sebesar 118.301 hektar, atau 28,8\% dari seluruh kawasan. Zona rimba mengalami kebakaran paling luas, yaitu 40.827 hektar, disusul dengan zona rehabilitasi 34.859 hektar, kemudian zona tradisional 16.955 hektar, zona inti 15.956 hektar, zona pemanfaatan sebesar 1.927 hektar, dan zona khusus seluas 10.816 hektar yang merupakan kawasan yang selalu dimanfaatkan oleh masyarakat sekitar dan hampir setiap tahunnya mengalami kebakaran.

Kebakaran masih disebabkan oleh faktor manusia, karena di sekitar kawasan dikelilingi desa yang masih ada aktivitas manusianya. Sumber api berasal dari desa sekitar, seperti Desa Sungai Cabang dan Desa Sungai Perlu. Penggunaan api itu dilakukan masyarakat untuk perburuan satwa dan pembukaan akses untuk mencari ikan. ${ }^{58}$ Pengawasan dan pengamanan kawasan yang dari jumlah personil polhut masih kurang dan juga karena pihak taman nasional kurang tanggap dalam menangani dan melakukan pencegahan kebakaran yang akhirnya meluas. ${ }^{59}$

Aktivitas perambahan yang dilakukan oleh masyarakat seperti perburuan, mencari ikan, dan illegal logging, menunjukkan penurunan pada tahun 2016 hingga 2017. Ada sekitar 18 kasus di tahun 2016, dan jumlah yang sama di tahun 2017, yang terdiri dari illegal logging, perburuan satwa, dan masyarakat yang mencari ikan di dalam kawasan. Kemudian, aktivitas perambahan hutan tersebut menunjukan jumlah yang tinggi pada tahun 2015, yakni 37 kasus, tahun dimana kebakaran besar terjadi di Tanjung Puting. Aktivitas tersebut dilakukan oleh masyarakat yang tinggal di sekitar taman nasional, dan terjadi baik di luar maupun di dalam kawasan taman nasional, dan telah mengancam kelangsungan ekosistem di dalam kawasan taman nasional. ${ }^{60}$ Kebakaran yang disertai dengan adanya aktivitas perambahan hutan ditengarai menjadi penyebab utama rusaknya beberapa area hutan rawa gambut Tanjung Puting. ${ }^{61}$

Pada tahun 2012, telah terjadi perubahan luas kawasan di Taman Nasional Tanjung Puting. Berdasarkan SK Menteri Kehutanan Nomor SK.529/Menhut-II/201262, luas kawasan Taman Nasional Tanjung Puting menjadi 408.287,51 hektar, yang sebelumnya memiliki luas 415.040 hektar. Ada empat desa yang di enclave-kan atau dikeluarkan dari kawasan, yaitu Desa Teluk Pulai, Desa Tanjung Harapan, Desa Sungai Cabang, dan Desa Sungai Perlu. Desa-desa tersebut, sebelumnya memang berada di luar taman nasional, kemudian setelah SK Penunjukan 687 masuk ke dalam kawasan dan dikeluarkan kembali melalui SK 529 ini. Bentuk kawasan kini melebar lebih luas ke sisi sebelah timur taman nasional. ${ }^{63}$

\section{Berdasarkan}

SK.529/Menhut-II/2012,

luas kawasan hutan Kalimantan Tengah sekitar 12.719.707 hektar atau $82,45 \%$ dari luas provinsi, yang terdiri atas KSA dan KPA 1.630.828 hektar,

\footnotetext{
Wawancara Penulis dengan Robert F. Yappi, GIS Department, Orangutan Foundation International, tanggal 29 Maret 2017.

Wawancara penulis dengan Saut Manalu, Kepala SPTN Wilayah I, tanggal 11 April 2017.

Nofella Mahardika, 2016, "Deforestasi dan Fragmentasi Hutan di Taman Nasional Tanjung Puting dan Sekitarnya", Skripsi, Program Studi Biologi, Sekolah Ilmu dan Teknologi Hayati, Institut Teknologi Bandung, hlm.40.

61 Mary Rose C. Posa, et al., "Peat Swamp Forest Birds of The Tuanan Research Station, Central Kalimantan, Indonesia, With Notes on Habitat Specialists", Forktail, Vol. 28, hlm.29.

62 Lihat Surat Keputusan Menteri Kehutanan Nomor SK.529/Menhut-II/2012 Tentang Perubahan Atas Keputusan Menteri Pertanian Nomor 759/Kpts/UM/10/1982 Tentang Penunjukan Areal Hutan di Wilayah Provinsi Daerah Tingkat I Kalimantan Tengah Seluas 15.300.000 Hektar Sebagai Kawasan Hutan.

63 Wawancara Penulis dengan Fajar Dewanto, Field Director, Orangutan Foundation International (OFI) tanggal 3 April 2017.
} 
dan telah terjadi pelepasan kawasan hutan untuk pemenuhan permintaan wilayah administrasi daerah dalam bentuk Areal Penggunaan Lain (APL) mencapai 7,7 juta hektar di 20 provinsi, termasuk Kalimantan Tengah. ${ }^{64}$ Pihak taman nasional saat itu sebenarnya mengakomodasi kebutuhan masyarakat, karena sebelum di enclave, masyarakat merasa takut untuk melakukan kegiatan bertani dan cocok tanam. ${ }^{65}$ Setelah dibuat nota kesepakatan yang ditandatangani oleh Bupati dan pihak desa, maka desa-desa itu menjadi enclave dan kemudian statusnya berubah menjadi (APL). Hanya Hutan Produksi yang terdegradasi dan/atau sudah tidak berproduksi lagi yang dapat dilepaskan dan dikategorikan sebagai $\mathrm{APL}^{66}$, dan ketiga desa tersebut merupakan area bekas HPH PT.Hezubasah seluas 90.000 hektar.

Tabel 4. Daftar Perusahaan Perkebunan Kelapa Sawit di Taman Nasional Tanjung Puting. ${ }^{67}$

\begin{tabular}{llll}
\hline No & $\begin{array}{l}\text { Zona Taman } \\
\text { Nasional }\end{array}$ & Luas Area & Perusahaan Perkebunan \\
\hline 1 & Tanjung & $\begin{array}{l}\text { Enclave 1200 hektar, untuk perkebunan } \\
\text { 900 hektar. }\end{array}$ & $\begin{array}{l}\text { PT Andalas Sukses Makmur (Grup } \\
\text { Bumitama Gunajaya Agro) }\end{array}$ \\
\hline 2 & Teluk Pulai & $\begin{array}{l}\text { Enclave 6000 hektar, untuk perkebunan } \\
\text { 4000 hektar. }\end{array}$ & \\
\cline { 1 - 3 } 3 & Sungai Cabang & $\begin{array}{l}\text { Enclave 12.000 hektar, 7200 hektar } \\
\text { untuk perkebunan. }\end{array}$ & PT Kumai Sejahtera \\
\hline
\end{tabular}

Pada awalnya pihak pengelola taman nasional menginginkan agar desa itu bisa dimanfaatkan sebaik mungkin oleh masyarakat, tetapi seiring berjalannya waktu, ada perusahaan-perusahaan perkebunan kelapa sawit yang masuk ke beberapa daerah APL tersebut, yaitu PT Andalas Sukses Makmur (Grup Bumitama Gunajaya Agro (BGA)), dan PT Kumai Sejahtera. ${ }^{68}$

Situs Ramsar yang menjadi rumah bagi orangutan ini harus menghadapi ancaman dari perkebunan kelapa sawit, yang telah membuat kanal di gambut. Ekosistem gambut yang sudah terbuka menjadi kanal menyebabkan fungsi hidrologi alamiahnya menjadi tidak stabil. Konversi gambut untuk perkebunan sawit meningkatkan risiko kerusakan tanah dan emisi karbon, serta penurunan keanekaragaman hayati. Secara alamiah kondisi gambut itu basah, dan bentuknya seperti ada kubah yang isinya adalah air. Kubah gambut inilah yang dicacah atau dibuat drainase yang mengakibatkan hilangnya daya tumpu gambut oleh air (storage), menurunnya permukaan tanah (subsiden), dan jika tidak ada inflow dari hujan, maka gambut akan rentan terbakar. ${ }^{69}$

Masalah paling serius terhadap keberlangsungan lahan basah adalah pemanfaatannya yang tidak berkelanjutan (unsustainable use of wetland resources). ${ }^{70}$ Oleh karena itu, perlu upaya untuk menjaga lahan basah agar terus lestari, dan pelaksanaan pelestarian juga harus terus dibenahi agar tidak terjadi pengurangan atau perusakan lahan basah lebih jauh lagi dimasa yang akan datang. Lahan basah yang rapuh dan sensitif ini, keberadaannya sangat tergantung pada cara pemanfaatan dan usaha pelestariannya. Karena fungsinya yang penting dan strategis ini maka perlu kesadaran bersama untuk menyelamatkan lahan basah.

64 Walhi, 2015, Analisis Kebijakan Penundaan Pemberian Izin Baru dan Penyempurnaan Tata Kelola Hutan Alam Primer dan Lahan Gambut, Kemitraan Partnership, Jakarta, hlm.4.

65 Wawancara Penulis dengan Akhmad Farid, Bidang Pengendalian Perubahan Iklim, Balai Taman Nasional Tanjung Puting, tanggal 6 April 2017.

66 Eko N. Setiawan, et.al., 2016, "Opposing Interests in The Legalization of Non-procedural Forest Conversion to Oil Palm in Central Kalimantan, Indonesia", Land Use Policy, Vol. 58, hlm.474.

Ibid., hlm. 477 .

Ibid.

Wawancara Penulis dengan Azwar Ma'as, Dosen Fakultas Pertanian UGM, 18 Mei 2017.

Yus Rusila Noor, 2007, Pengelolaan Lahan Gambut Berbasis Masyarakat di Indonesia, Wetlands International Indonesia, Bogor, hlm.82. 


\section{Kesimpulan}

Ketentuan-ketentuan di dalam Konvensi Ramsar telah dilaksanakan dan ditransformasikan ke dalam peraturan perundang-undangan di Indonesia. Namun, dalam praktik, masih lemahnya komitmen pemerintah sehingga berimplikasi pada masih ditemukannya peraturan yang tidak sinkron, sehingga belum dapat melaksanakan komitmen pemanfaatan lahan basah secara bijaksana dan berkelanjutan.

Pelaksanaan Konvensi Ramsar dalam perlindungan dan pengelolaan ekosistem gambut di Tanjung Puting yang belum optimal disebabkan oleh faktor internal dan eksternal. Faktor internalnya adalah kurangnya sosialisasi kepada seluruh stakeholders, terbatasnya sumber daya manusia, minimnya anggaran, dan masih lemahnya pengawasan, dan koordinasi antar institusi. Sedangkan faktor eksternalnya yakni masih ditemukannya aktivitas perambahan oleh masyarakat yang masih menggunakan api untuk perburuan satwa dan pembukaan akses untuk mencari ikan, serta illegal logging, yang terjadi baik di luar maupun di dalam kawasan taman nasional, sehingga pada tahun 2015 telah terjadi kebakaran yang menghanguskan hampir sepertiga luas kawasan. Kebakaran yang disertai dengan adanya aktivitas perambahan hutan ditengarai menjadi penyebab utama rusaknya beberapa area hutan rawa gambut Tanjung Puting. Keberadaan perkebunan kelapa sawit yang berada di daerah APL yang telah membuat kanal di gambut, juga menyebabkan fungsi hidrologi alamiahnya menjadi tidak stabil dan akan rentan terbakar. Selain itu, juga dapat meningkatkan risiko kerusakan tanah dan emisi karbon, serta penurunan keanekaragaman hayati. Masalah paling serius terhadap keberlangsungan lahan basah yang rapuh dan sensitif ini adalah pemanfaatan yang tidak berkelanjutan (unsustainable use of wetland resources), sehingga keberadaannya sangat tergantung pada cara pemanfaatan dan usaha pelestariannya

Pemerintah perlu melakukan harmonisasi peraturan perundang-undangan yang telah ada untuk mendukung pelaksanaan Konvensi Ramsar di Indonesia. Peraturan mengenai perlindungan Situs Ramsar dan ekosistem lahan basah terutama yang menyangkut dengan fungsi lindung dari ekosistem gambut sebaiknya menggunakan pengertian dan kriteria yang konsisten, agar tidak terjadi perbedaan penafsiran. Terkait definisi, kriteria, dan daftar Situs Ramsar di Indonesia yang ada di dalam PP Rencana Tata Ruang Wilayah Nasional perlu diserasikan dengan muatan yang ada di dalam Perpres Rencana Tata Ruang tiap pulau, terutama Kalimantan, yang menjadi lokasi dari Situs Ramsar. Pemerintah harus melakukan pengawasan yang optimal, agar seluruh pihak dapat menjamin kelestarian dan pemulihan ekosistem gambut. Pemerintah juga dapat mengupayakan Revisi UU Nomor 5 Tahun 1990 agar segera diselesaikan, mengingat ketentuan mengenai Konvensi Ramsar telah diusulkan untuk dimuat dalam RUU tersebut. Untuk menunjukan komitmen yang lebih tinggi, Pemerintah dapat mengupayakan juga Peraturan Pemerintah mengenai Konservasi Lahan Basah, yang fokus dalam menghimpun seluruh potensi ekosistem lahan basah yang dimiliki.

Kementerian Lingkungan Hidup dan Kehutanan selaku Administrative Authority dan National Focal Point Konvensi Ramsar di Indonesia perlu melakukan sosialisasi secara intensif kepada semua pihak, masyarakat, mitra dan pihak pengelola taman nasional itu sendiri agar tercipta sense of belonging, ownership, dan senses of pride. Sosialisasi dapat dilakukan melalui kegiatan berupa penyuluhan hukum, workshop dan pendidikan konservasi lahan basah, serta sosialisasi kebijakan dan peraturan mengenai lahan basah dan Situs Ramsar di Indonesia. Sosialisasi keanekaragaman hayati ekosistem lahan basah yang dilindungi perlu dilakukan kepada seluruh masyarakat di sekitar kawasan, agar tercipta kesadaran dan pemahaman yang memadai atas Konvensi Ramsar. Koordinasi terkait perencanaan, penganggaran, dan pelaksanaan di tiap sektor harus terus ditingkatkan. Peran NGO, perguruan tinggi, serta swasta, sangat dibutuhkan terutama dalam peningkatan pemberdayaan 
masyarakat, pengembangan penelitian dan pendidikan konservasi lahan basah. Pihak taman nasional perlu segera menyusun Rencana Pemulihan Ekosistem, dan melakukan inventarisasi gambut seluruh kawasan, terutama mengenai kedalaman hingga kondisi gambut yang telah terdegradasi. Gambut yang telah rusak, terutama pasca terbakar, perlu segera dilakukan pemulihan.

\section{DAFTAR PUSTAKA}

\section{A. Buku}

Balai Taman Nasional Tanjung Puting, 1999, Rencana Pengelolaan Taman Nasional Tanjung Puting (1999-2024) Buku II (Data, Proyeksi, dan Analisis), Balai Taman Nasional Tanjung Puting, Kumai.

Birnie, Patricia, et al., 2009, International Law \& The Environment, Oxford University Press.

Direktorat Kawasan Konservasi dan Bina Hutan Lindung, 2015, Pedoman Implementasi Konvensi Ramsar di Indonesia, Direktorat Jenderal Perlindungan Hutan dan Konservasi Alam Kementerian Lingkungan Hidup dan Kehutanan, Jakarta.

Direktorat Konservasi Keanekaragaman Hayati, 2008, Konvensi dan Kerjasama Internasional Bidang Konservasi Keanekaragaman Hayati, Kementerian Kehutanan, Jakarta.

Komite Nasional Pengelolaan Ekosistem Lahan Basah, 2004, Strategi Nasional dan Rencana Aksi Pengelolaan Lahan Basah Indonesia, Kementerian Lingkungan Hidup.

Osaki, Mitsuru, et al., 2016, Tropical Peatland Ecosystems, Springer, Japan.

Noor, Yus Rusila, et al., 2007, Pengelolaan Lahan Gambut Berbasis Masyarakat di Indonesia, Wetlands International Indonesia, Bogor.

Sands, Philippe, 2003, Principles of International Environmental Law, Cambridge University Press.

Secretariat Ramsar Convention, 2016, An Introduction to The Convention on Wetlands, Ramsar Convention Secretariat, Gland, Switzerland.

\section{B. Jurnal}

Batanjski, Vera, et al., "Critical Legal and Environmental View on The Ramsar Convention in Protection from Invasive Plant Species: An Example of The Southern Pannonia Region", International Environmental Agreements: Politics, Law and Economics, Springer Nature, Vol.16, Issue 6, 2016.

Posa, Mary Rose C.Posa, "Peat Swamp Forest Birds of The Tuanan Research Station, Central Kalimantan, Indonesia, With Notes on Habitat Specialists", Forktail, Vol. 28, 2011.

Ansari, Haseeb, et al., 2011, "Ramsar Convention and Convention on Biological Diversity as Mechanism for Promoting Biodiversity Conservation of Malaysian Wetlands", Journal of Applied Sciences Research, Vol. 7 , No. 13, 2011.

Finlayson, Max, et al., "The Ramsar Convention and Ecosystem Based Approaches to the Wise Use and Sustainable Development of Wetlands", Journal of International Wildlife Law \& Policy, Vol. 14, No.3-4, 2011.

Merdekawati, Agustina, et al., "Analysis on Indonesia's fulfillment of Obligations Rising from International Treaties", Jurnal Mimbar Hukum, Vol. 28, No. 3, 2016.

Prahalad, Vishnu N., et al., "Implementation of the Ramsar Convention on Wetlands in Tasmania, Australia", Journal of International Wildlife Law \& Policy, Vol. 13, No. 3, 2010.

Setiawan, Eko N., et.al., "Opposing Interests in The Legalization of Non-procedural Forest Conversion to Oil Palm in Central Kalimantan, Indonesia", Land Use Policy, 
Vol. 58, 2016.

Pramudianto, Andreas, "Kawasan Lahan Basah dalam Konsep Hukum Global dan Keberadaannya di Indonesia", Jurnal Lingkungan dan Pembangunan, Vol. 14, No. 1, 2014.

\section{Hasil Penelitian/Tugas Akhir}

Mahardika, Nofella, 2016, "Deforestasi dan Fragmentasi Hutan di Taman Nasional Tanjung Puting dan Sekitarnya", Skripsi, Program Studi Biologi, Sekolah Ilmu dan Teknologi Hayati, Institut Teknologi Bandung.

Novita, Dian, 2016, "Penilaian Risiko Bencana Ekologis Taman Nasional Tanjung Puting Kalimantan Tengah", Tesis, Program Pascasarjana Program Studi Magister Manajemen Bencana Universitas Gadjah Mada, Yogyakarta.

Qiptiyah, Maryatul, 2008, "Struktur Komunitas Burung Pantai Migran di Berbagai Tipe Habitat Kawasan Lahan Basah Tambaksari, Sayung, Demak", Tesis, Program Studi Ilmu Kehutanan, Sekolah Pascasarjana UGM.

\section{Internet}

Wetlands International, "Policy Analysis of PP No.71/2014",https://indonesia.wetlands.org/ publications/policy-analysis-of-pp-712014/, diakses tanggal 20 Januari 2017.

\section{E. Peraturan Perundang-undangan}

Undang-Undang Nomor 5 Tahun 1990 tentang Konservasi Sumber Daya Alam Hayati dan Ekosistemnya, (Lembaran Negara Republik Indonesia Tahun 1990 Nomor 49, Tambahan Lembaran Negara Republik Indonesia Nomor 3419)

Undang-Undang Nomor 24 Tahun 2000 tentang Perjanjian Internasional, (Lembaran Negara Republik Indonesia Tahun 2000 Nomor 185, Tambahan Lembaran Negara Republik Indonesia Nomor 4012)

Undang-undang Nomor 32 Tahun 2009 tentang Perlindungan dan Pengelolaan Lingkungan Hidup, (Lembaran Negara Republik Indonesia Tahun 2009 Nomor 140, Tambahan Lembaran Negara Republik Indonesia Nomor 5059)

Keputusan Presiden Republik Indonesia Nomor 48 Tahun 1991 tentang Pengesahan Convention on Wetlands of International Importance Especially as Waterfowl Habitat.

\section{F. Konvensi Internasional}

Conventions on Wetlands of International Importance, Especially as Waterfowl Habitat 1971. 